\title{
The Exploration of Flipped Classroom in College Chinese Teaching
}

\author{
Yang Xu \\ Institute of Literature and Law, Qilu University of Technology, University Town, Jinan, China \\ ncyy1234@126.com
}

Keywords: Flipped Classroom, College Chinese, Teach and Learn

\begin{abstract}
There are many shortcomings in the traditional teaching of College Chinese, which need to be reformed. As a new classroom teaching mode, the Flipped Classroom has become an important part of the innovation of university classroom teaching in the aspects of teaching ideas, learning process and learning thinking. In this paper, the lesson "Shan gui" as an example, we practice the Flipped Classroom in College Chinese, and put forward the Flipped Classroom of the operational and practical recommendations in the specific teaching process.
\end{abstract}

As a new form of classroom teaching, Flipped Classroom originally tried by the United States of America Colorado Woodland Park High School. "Khan Academy" has promoted it on the web. And then the Flipped Classroom is quickly popular in many colleges and universities in the United States. In a short span of ten years, this new teaching model has become the focus of attention in the global education community with active educational philosophy. In recent years, "flip classroom" has gradually introduced into the field of education in China. With the continuous development of China's information technology, colleges and universities, secondary schools, primary schools and many other education levels have recognized its revolutionary value of traditional teaching methods. With the continuous development of the educational system and teaching level of colleges and universities, there is an urgent need to reform the original teaching mode. As a university college course, How to introduce a new teaching concept to enrich the original teaching methods is an urgent problem to be solved.

\section{The Analysis of the Present Situation of College Chinese}

At present, College Chinese is a humanities quality education courses, for non-Chinese students in the national colleges and universities. designed to improve students' aesthetic ability and language skills. I have been engaged in College Chinese teaching and research work for many years. As a popular subject, College language plays a very important role for the promotion of traditional Chinese culture, enhancing mother tongue ability, and cultivating college students' humanistic accomplishment. Because of its systematic and independent settings, College Chinese crossed the boundaries of literature and language, but also the boundaries of China and foreign. College Chinese contains not only Chinese language, but also human culture.[1] Therefore, the College Chinese has a very important practical significance, for college students, especially science and engineering students to enhance the personal ability. At the same time, many schools, disciplines set up College Chinese. But the teaching status and effect is not optimistic.

First, the positioning of the course is not clear.

It is completely different from the middle school language class. The middle school language course is set as the main course for students to participate in the college entrance examination. The course content, teaching methods, etc. are based on college entrance examination, focusing on knowledge and answer skills. College Chinese is a humanistic quality course to improve students' humanistic accomplishment in colleges and universities. It focuses on the ability of students to understand and enhance the use of native language. Therefore, it's positioning is not simply 
imparting knowledge, but literary cultivation and appreciation. However, at present, the actual teaching of university language in colleges and universities still focuses on the specific literary knowledge points, and is less in the analysis of literary works and the refinement of literary spirit.

Second, teaching model in the classroom is monotonous.

The traditional way of teaching, teacher saying and students listening, is increasingly tied to the vitality of the course. On the one hand, the teacher is prone to slackness in the process of explaining the same content many times. On the other hand the students are likely to cause aesthetic fatigue and distract attention.

Third, students take the initiative to learn poorly.

It should be said that this problem is not only reflected in the College Chinese courses. With the popularity of smart phones and network technology, "bow family" occupies the majority of the classroom. For general education, due to the lack of student's attention, this situation is more obvious, and show serious year after year.

Because of the problem above, we should really explore a new form of humanistic courses teaching, that can fully mobilize students to learn the initiative of the university language courses.

Your paper will be part of the journals therefore we ask that authors follow the guidelines explained in this example, in order to achieve the highest quality possible.

Be advised that papers in a technically unsuitable form will be returned for retyping. After returned the manuscript must be appropriately modified.

\section{The Differences between Flipped Classroom and Traditional Classroom}

\section{Differences in Teaching}

The primary difference between Flipped Classroom and traditional teaching is teaching ideas. The traditional teaching is focused on the learning type of teaching, and Flip Classroom teaching tends to study type of teaching. It should be said that the teaching idea of the Flipped Classroom is similar to the master's degree even the doctor degree in our country. Of course, the content is a lot easier. The results under the influence of different ideas are fundamentally different. Traditional teaching focuses on the accumulation of knowledge and the results of the final exam. Flipped Classroom pays attention to students' promotion of individual thinking ability and comprehensive quality.

\section{Differences in learning process}

The traditional teaching process only includes the teacher's speech and the student's learning. After a long time, the teacher is tired of their speech. Students are not interested in learning. The process of Flipped Classroom is to study, and then discuss. Self-study materials, audio and video, and related information published on the information platform by teachers. Teachers and students are mainly interactive Q\&A and exchange of questions in the classroom. So students pay more attention to their own study in Flipped Classroom than in traditional classroom.

\section{Differences in Students' thinking}

In the traditional classroom students passively accept the knowledge, mechanically recite the main points. In Flipped Classroom the mode of thinking of students' classroom learning is fundamentally changed, from what to why. Flipped Classroom leads students to gradually develop awareness of the problem and participation. This change exactly solves the negative impact of exam-oriented education on students.

\section{The Case of College Chinese in Flipped Classroom}

In order to effectively improve the teaching quality of College Chinese, the author gives an example of studying Flipped Classroom. This paper selected the lesson "Shan Gui" in "College Chinese" (Song Yan, Bao Yan editor, Shandong People's Publishing House, 2009 edition), to design the Flipped Classroom. Flip the classroom should include three parts, pre-class study, 
communication in classroom, and after-class reflection. Part One and Three need to use modern network platform (this course mainly use QQ group and Weixin group).

\section{Preview}

Preview in the implementation of Flipped Classroom is an important part. There is no teacher involved in this part, but the role of the teacher is very important. Teacher should provide related content materials as full as possible to students.

"Shan Gui" is a representative of Qu Yuan "Nine Songs." It describes a goddess in mountains, who goes to an appointment. The author creates an ethereal artistic realm with rich imagination. But students know Qu Yuan far more than the poem. Therefore, in the early pushing process, the teacher should step by step describe Qu Yuan's life, thought and political environment into the poem "Shan Gui". Only in this way students can understand the meaning of this poem. In this part the video and courseware are provided, including not only courseware (PowerPoint) in the traditional classroom, but also the video introducing Qu Yuan, the Warring States Period and the Chu Kingdom (This course uses the video excerpt from the hit TV series "The Legend of Miyue"). The videos play in less than 15 minutes. This course is mainly prepared for undergraduates of science and engineering, and the main purpose of the course is to popularize literary knowledge and improve literary appreciation skills. Therefore, early information is provided as much as possible to choose intuitive and popular video. Its purpose is to motivate students' motivation, to attract students with the popular elements of the film and television, closer distance between the "Shan Gui" and students.

\section{Communication in classroom}

As a fundamental difference from the traditional classroom mode, the teaching mode is more emphasized in the form of teacher-student interaction. The role that teachers play in this part is to propose tasks and lead students to explore.

First, students are grouped according to their research interests freely. Several students selected from each group make speeches in class for their previous learning experiences. The teacher keep abreast of student learning in this way. At the same time, the teacher asked questions about the important words in "Shan Gui" to check the students' learning status, Such as "Biao duli xi shan zhi shang, yun rong rong xi erza ixia." "Lei tian tian xi yu ming ming, yuan jiu jiu xi you xie ming." For Chinese ancient poetry, the understanding of the meaning of words is the basis of all learning processes.

Second, the teacher asked questions concerning the ideology and structure of Qu Yuan and "Shan Gui". It includes Qu Yuan's basic experience, patriotism, the understanding of "Shan Gui" and so on. Students discuss and answer in groups. In this process, teachers should participate in specific group discussions, listen to their thoughts and answer their questions.

Third, the teacher interacts and answers questions about the students' class responses. In this process, the teacher should make the students further clarify the life ideal of Qu Yuan and the complex feelings between him and the ruler, meanwhile understand the position and function of "Shan Gui" in the whole process of Qu Yuan's creation. This session takes about half an hour duration in the entire two hours of course teaching. Different from the students' expression and the exchange between teachers and students, the teaching methods in this part are summarized and refined by the teachers.

\section{Reflections after class}

As the requirements of college Chinese, the teacher arranged the course work after learning "Shan Gui". The purpose is to encourage students to further deepen the content discussed and learned in the classroom. The paper of the study of "Shan Gui" is necessary to students. This can help students master the knowledge they have learned, at the same time, guide students to put their thoughts into paper, and enhance their writing skills. In this part, the network interactive platform has also become an important channel for teachers and students to communicate. Students are encouraged to upload their works to the QQ group, and accept the common judgments of teachers 
and classmates. In this way, job performance is fair and opens while promoting students learn each other and avoiding copying homework each other.

\section{Think of Popularizing the Flipped Classroom}

\section{Feasibility of Using the Flipped Classrooms}

At present, the Flipped Classroom in our college teaching environment is very viable. As a teaching mode that just appeared in recent years, the Flipped Classroom depends on the smooth implementation of the development and popularization of modern information technology. At this stage, colleges and universities in our country basically have the corresponding hardware resources. As we all know, the Flipped Classroom is characterized by the teacher's teaching process beginning before the class. This requires that teachers pass the courseware of each course to students before the class, so that students can receive knowledge information more freely and flexibly during the after school hours. With the rapid development of the Internet in China in recent years, the platform for the exchange between students and teachers is undergoing dramatic changes. E-mail, micro blog, QQ software that we are using for recent years is being gradually replaced by the current WeChat, the webcast. For the modern university campuses that have been popularized by smartphones, more after-95 college students tend to accept new information through the WeChat public account, webcasting and online video. This new phenomenon is more conducive to the Flipped Classroom. Previously, teachers uploaded videos and slides to the website, and now we can make use of the WeChat public account number of regular updates, online video updates. We edit the content of the classroom into a vivid and intuitive video material. To be sure, rich and intuitive video information is more attractive to contemporary college students' attention. The effect of teachers simply explanation is worse than it.

\section{The Necessity of Using the Flipped Classroom}

In our opinion, under the current "Internet +" wave of social reforms, the teaching methods and specific teaching methods of colleges and universities must also meet the requirements of the new time. As the most active place for thinking and culture in the whole society, colleges and universities not only serve as academic ivory towers, but also should be laboratories where new technologies and new methods are put into practice first. With the development of the times, the freshmen entering colleges and universities basically belong to after-95 or even after-00. And they have huge differences in learning methods and daily life compared with those students four or five years ago. At present, the teachers' effort to explain and the students' playing mobile phones in the class have become a thorny issue that plagues numerous university teachers. Many students just think of courseware as a pre-test good weapon. The teacher's vivid explanation can not compare with the charm of online video and online games. This makes the learning of students greatly reduced. It is difficult to fully absorb the knowledge of teachers to explain because of the poor state and week learning enthusiasm of students. It can be seen that the popularizing Flipped Classroom teaching methods is a certain inevitability and urgency in the current teaching situation of colleges and universities. On the one hand, in the Flipped Classroom, the teacher sends the courseware and related videos to students in advance, and students can understand the main points of this course before the lesson. This method of providing teaching knowledge before class basically conforms to the new way of pursuing free individuality life for the new generation of undergraduates. Students can complete the pre-study and study of class knowledge in the more relaxed and autonomous learning atmosphere. On the other hand, teachers in the classroom change speaking to listening. It forces more students to join the class discussion. So teachers not only exercise the students' ability to learn the knowledge, but also effectively improve the quality of classroom teaching. By the way, Flipped Classroom drastically reduces the frequency with which students play cell phones in class.

\section{The Internal Adaptability of the Flipped Classroom and College Chinese Teaching}

The Flip Classroom is very different from the traditional teaching model, which requires teachers 
to actively study and progress to keep up with changes in the times.

Compared to the traditional classroom teaching, Flipped Classroom gives the new vitality of College Chinese. For College Chinese courses which focus on improving humanistic accomplishment, the use of Flipped Classroom can better reflect the literary aesthetic characteristics of the course, enable students to better break through teacher's knowledge authority and form a multi-dimensional thinking with individual characteristics. It also helps to build new type of teacher-student relationship, in which teachers gradually change from knowledge transferors to developers of teaching resources, instructional helpers, and mentors.

The main teaching contents are all representative literary works of different historical periods in China. The contents of the class mainly include the explanations of specific literary works, the introduction of historical background, the author's personal experiences. It can be said that under the existing Internet environment in our country, these general knowledge points can be fully mastered by the students in advance. Students can learn a full range of knowledge points in various ways, such as internet search, academic website search and so on. On this basis, teachers will then send courseware and related video information to students in advance, which can fully realize the course information in the pre-class stage. In our opinion, it is particularly important for humanities disciplines to collect and organize pre-class information. Students thus have a broader theoretical perspective, not only have individual, independent knowledge points.

\section{The Problems of the Flipped Classroom in practice}

It should be said that the Flipped Classroom has undoubtedly infused the vitality of the past dull teaching methods. However, during the practical teaching at this stage, the problems encountered in the Flipped Classroom are also outstanding. Teachers still need to constantly adapt and learn in practice.

The biggest difference from the traditional preparation and teaching is that the Flipped Classroom needs to share and spread the information with multimedia devices, even with self-made audiovisual materials. The requirements of the teacher are obviously improved, because of the operation of multimedia equipment and the production of audio and video materials. The difficulty of teaching is also increased accordingly. Thus the traditional teaching, in which a teacher single prepare the lessons, is no longer applicable. For teachers, there is an urgent need to form a close course group and use the power of the team to prepare courses. In the meantime, Flipped Classroom is also a challenge for students who are used to unilaterally receiving information. Students have different learning abilities, and also have differences in the ability to Flipped Classroom. Therefore, for the teaching process of College Chinese, the Flipped Classroom and traditional classroom teaching should be integrated gradually. Teachers should help students study from passive to active learning.

\section{References}

[1] Zhang Fugui, Disciplinary Position and Functional Characteristics of College Chinese Education[J] China University Teaching 2014 (1).

[2] He Zhaoyang, Ou Yufang, Cao Qi, Inspiration of USA Universities' Inverted Classroom Teaching Model[J], Research in Higher Education of Engineering, 2014 (2).

[3] He Kekang, From the Essence of "Flipped Classroom" See the Future Development of "Flipped Classroom" in China, E-education Research 2014 (7)

[4]The flipping classroom.[2014-4-10].http://educationnext.org/the flipping classroom.html.

[5]Jonathan Bergmann and Aaron Sams. Flip Tour Classroom[M].America, International Society for Technology in Education,2012:21-55. 